Clinical Social Work Journal

Vol. 16, No. 2, Summer 1988

\title{
DIVORCED PARENTS AND ADOLESCENT GIRLS: THE BOUNCING BALL
}

\author{
Rebecca Lohr
}

\begin{abstract}
In clinical work with divorced families and children, the continuing unfolding of developmental and familial issues has been observed over the spectrum of many years. While custody disputes soon after a divorce often reflect a playing out of control battles and ambivalence between the parents, changes in residence that occur during adolescence, years after a divorce, are seen as reflecting ongoing parental conflicts as well as phase specific adolescent developmental and divorce-related factors. Theoretical issues that deal with the resolution of adolescent developmental tasks in divorced families are explored and clinical experiences with these adolescent girls whose parents divorced during their earlier years are presented.
\end{abstract}

In our clinical work with divorced families and children, we have observed the continuing unfolding of developmental and familial issues in a myriad of ways. Many authors, including Wallerstein and Kelly (1977), have noted that divorce is not a circumscribed event, but a process that spans several years. External and internal changes evolve over the course of many years that involve fluctuating external realities combined with internal developmental issues. One of the most poignant of these concerns is where and with whom the child of divorce will reside. Custody disputes soon after a divorce often reflect a playing out of control battles and ambivalence between the parents. Different issues emerge as children whose parents divorced early in their lives become adolescents. The adolescent phase presents challenges in all families, whether intact or divorced. We will explore a particular facet of the adolescent struggle, that of the conscious and unconscious motivations and forces at work in divorced parents and in adolescents who move from one parental home to the other. Wallerstein (1985) reported in a tenyear follow-up study of 40 young adults currently 19 to 29 years of age that $20 \%$ of them had gone to live with the departed parent for a period 
of time, and an additional $12 \%$ had moved back and forth several times between the mother's home and the father's home during adolescent years. While our clinical experience has included work with both male and female adolescents, we will focus on issues and clinical material from adolescent female patients and their families.

\section{Normal Adolescent Developmental Tasks}

As children enter adolescence they face new and challenging developmental tasks. These include changing relationships to original love objects, described by Anna Freud (1958) as the loosening of ties to the infantile oedipal objects. Peter Blos (1962) speaks of the second individuation process, or the disengaging of ties to the original objects. There is a concomitant and increasing shift to objects outside of the family, with investment in peer relationships and relationships with parental surrogates. Laufer (1977) places emphasis on the adolescent's experiencing of his own body and awareness of sexual capacities, with the main function of adolescence being the establishing of a sexual identity. Erikson (1963) focuses on integration of identifications and character formation. He states that "formation of ego identity is more than the sum of childhood identifications. It is the accrued experience of the ego's ability to integrate all identifications with the vicissitudes of the libido, with the aptitudes developed out of endowment, and the opportunities offered in social roles" (p. 261). These tasks, while difficult for all adolescents to achieve, pose additional challenges for adolescents who have experienced disruptions and discontinuity in ties to parental objects.

Adolescents voice in varied ways their search for resolutions of a range of affects and conflicts related to divorces that occurred during their earlier years. Some participate in an illusion that a reunion experience over a period of time with the other parent will undo the disruptions, disappointments, aggressions, and transgressions of the past. Most adolescents (the exceptions being where there is geographical proximity and joint custody) have missed out on the opportunity to test out their ambivalence toward and identifications with both parents on a day-to-day basis. In Adolescence Anna Freud (1958) mentions that the difference between normal development and psychopathology depends in part on whether the cathectic shifts in adolescence are gradual or sudden and precipitous. When gradual detachment from the parents is allowed to take place, the defenses are transitory, are less intense, and do not have an all or none quality. When the change is sudden, the sequence of events assumes more of a defensive and pathological quality rather than that of normal growth. Adolescents and divorced parents alike struggle with ways and means of meeting these challenging developmental tasks. We have had experience with a number of adolescents 
who have attempted to reengage with an absent parent by shifting from the primary custodial home to the other. While we are aware that there may be positive outcomes of some of these attempted reunions (in which case the adolescent may be less likely to present for service), our clinical experience reveals that many adolescents react with heightened narcissistic conflicts and depression when the environmental changes have negative outcomes. A similar phenomenon may be observed in adopted children who seek reunion with their natural parents to help them resolve identity issues. For all adolescents who have experienced total or partial object losses during childhood, the resolution of adolescent developmental tasks will pose particular challenges.

\section{Parental Developmental Tasks}

As adolescents develop more of their own identities and further the detaching process from parents, a reciprocal parental response occurs (Anthony, 1970). Parents of adolescents experience a resurgence of both pleasurable aspects of their own identity as seen in their children, and intensified old conflicts, in particular, increased ambivalence toward the adolescent, envy of the adolescent's emerging sexuality, and mourning of the functions associated with the parenting process (Derdeyn \& Waters, 1977). For parents who have divorced, there is much less builtin support by way of a marital relationship to provide a stable anchor when parental narcissism and authority are under challenge. Further, the divorce experience leaves residues of unresolved ambivalence between spouses. Children of divorce often become recipients of these residues as they approach and enter adolescence. In this stage, the identity formation becomes more evident and often leads to the perception of the child as similar to the ambivalently cathected ex-spouse (Chethik, Dolin, Davies, Lohr, \& Darrow, 1986).

Ambivalent struggles between adolescents and their parents are discussed at length in the literature. That parents react to their adolescent children's heightened identity conflicts, strivings for autonomy, and disengagements from parental objects with ambivalence is also recognized but not as widely discussed in terms of its clinical implications. Cohen and Balikov (1974) describe "a discreet parental response to adolescent phenomena which results in a wish on the part of parents to be rid of the adolescent" (p. 217). They further describe hostility as a component of attempts to maintain involvement as well as to achieve objectsubject distinction. Abdication of the parental role with adolescents may be a reaction to feelings of helplessness and powerlessness. Maintaining empathy with adolescents is a desirable but often hard to attain goal (Derdeyn \& Waters, 1977).

Elson (1984) writes of the fragmentation and loss of vigor within 
REBECCA LOHR

the nuclear self that may arise during parents' middle years. Narcissistic issues may emerge with greater force "as parents now experience competitive challenge, a need to bind the child more closely to their own ambitions and goals, or to abandon the role of parenthood while seeking solutions to their own difficulties" (p. 310). Threatened by the adolescent's strivings for self-definition and autonomy, the divorced parent's narcissistic equilibrium is particularly precarious, as there may be a resurgence of identity issues, drive regulation, and object choices that have more traditionally been seen as characteristics of the adolescent phase.

Divorced parents who have difficulty with their feelings toward the adolescent may have ready access to an alternative, that is, having the adolescent move to the other parent. On a manifest level, this may be presented by the primary parent as "giving my daughter a chance to know her father," or when the primary parent is the father, "My daughter needs a mother to see her through her adolescence." In some cases, for the adolescent to move to the other parent's may be the most desirable alternative. For others, there are more latent, unconscious motivations that will exert an impact on the eventual outcome. In additon, there are situations where the parent is more overtly dismissing of the adolescent's needs and rejecting of the adolescent in sending them to the other parent who is known to be incompetent.

Three cases will be presented and discussed. In the first two, the adolescent girls moved from their mothers' to their fathers' homes; in the third, the move was from father's home to mother's.

\section{CASE ILLUSTRATIONS}

\section{Parental ambivalence/adolescent narcissistic vulnerability}

Carol presented to the Child and Adolescent Psychiatry Service at the age of 16 with symptoms of depression, poor school performance and substance abuse. Her previously high level of functioning had been diminishing for approximately a year since returning from a six-month visit with her father. The evaluator was impressed with the eroticized description of Carol's relationship with her father and the subsequent total absence of contact between them. Although treatment was recommended she did not pursue therapy until a year later when at the age of 17 she had been advised that she would be unable to graduate with her high school class because of failing grades. A clear pattern had begun to emerge of her turning to alcohol at times of acute stress to obliterate painful affects associated with rejection and failure.

When Carol was 15, she had voiced her desire to go 1500 miles to 
live with her father, with whom she had only sporadic contact since her parents' divorce when she was five. This request had been fully supported by her mother who verbalized that she thought it would benefit Carol and her 13-year-old brother to get to know their father. Also, she had found the years of being a single parent very burdensome and welcomed the opportunity to be free of responsibility for the children so that she could pursue her own career and heterosexual relationships. More affect laden reasons emerged in parent guidance as she talked about never having been fully able to divorce Carol's father because every time she looked at Carol, she saw the father's image. The intensely ambivalent relationship she had with her husband had persisted in the relationship with Carol. She perceived herself unable to gratify the intense needs of either one for affective involvement and felt profoundly inadequate in relation to both of them. She felt drained and zapped of energy by Carol's emotional demands and having her gone was anticipated as a welcome relief. Carol also was overjoyed at the opportunity to get to know her father. She retained a mixture of highly positive and frightening fantasies and memories about him. While with her father, her feelings soured as she felt teased by him about her emerging sexuality and feminity, one moment being praised for her attractiveness and the next accused of being overweight. He took her to adult parties "like a date" and to the grocery store as his "live-in partner." Carol felt simultaneously excited and distressed by the feelings that stirred within her. She began a relationship with a man ten years her senior to take the heat off the interactions with her father. When she returned from his home by airplane after six months, she recalled getting drunk for the first time with an older man. Carol reexperienced as an adolescent many of the feelings she had originally experienced at the age of five when her parents separated and she had felt rejected by her father and emotionally abandoned by her depressed mother. Long-term, twice weekly therapy combined with antidepressants was recommended to help her deal with feelings of narcissistic injury and depression.

Early in treatment, Carol invested in the therapeutic relationship and seemed capable of developing insight into how her earlier experiences related to her present feelings about herself. After some initial testing out of the therapist's investment in her which she expressed by calling in sick as she had done with school attendance, she made a positive commitment to working on feelings of low self-esteem and fears of intimacy related to her anticipation of rejection and verbal castigation that she experienced with her father. Her fears often led her into an approach/avoidance pattern ending in isolative retreat from peer relationships. One very poignant, persistent memory emerged of her father swinging her high on a swing; she felt intense pleasure and security in 
REBECCA LOHR

his hands, only to tumble to the ground. She was able to perceive the repetition (and fear of repetition) of this scenario in her adolescent experiences. As she explored these issues, a relationship with a young man developed. Experiences, impulses, and affects when with her father had been blocked from conscious memory, but over time surfaced. She recalled his looking at Playboy magazines and comparing her (unfavorably) with the centerfold pictures. She wanted to be attractive to him, but vignettes recalled suggested fear that neither of them could control the impulses that might be triggered. Her need to undo her success and attractiveness emerged as a result of her guilt and anxiety over achievement and attention from males. She described her father as a bright, attractive, gregarious man who had significantly underachieved as a truck driver. She felt very identified with his personality characteristics and underachievement and struggled against identifying with her depressed, passive mother. As treatment progressed, Carol's underlying depression, which in part represented an internalization of the depressed mother, came more into focus. When Carol was eleven and developing breasts, her mother had undergone a mastectomy. She remembered intensified embarrassment at experiencing positive, pleasurable feelings associated with her own bodily development at the time her mother was mourning loss of a breast. This appeared also as a screen memory of pleasurable affects she had experienced during the oedipal phase when her parents were stressed about the divorce. Carol presented with strong unmet dependency needs vis-à-vis her mother that she had attempted to defend against with pseudomaturity and self-care since early childhood. Progressive, independent strivings during therapy were often followed by regressive, dependent longings in relation to her mother and in the transference. During the time after the divorce, Carol's mother had been quite depressed and on occasion threatened suicide, verbalizing to the children they were making her depressed and suicidal. Carol, at an early age, had become pseudomature in order not to be "a burden" to her mother and felt she had to be there to protect her mother. Identification with her mother's depression served defensively against her aggression toward her. Carol held herself responsible for her parents' divorce and her mother's subsequent depression. Therapy gave her the opportunity to rework some of these earlier childhood fantasies and perceptions in order for a more realistic perspective on herself and her parents to evolve.

Carol's contact with her father over the course of almost two years of therapy was limited to several telephone contacts. After receiving a telephone call from him in which she asked him about his history of depression, low-level job performance, and relationships, and told him that he needed therapy, she abruptly terminated treatment. The only reasonable interpretation appeared to be her need to leave the therapist ab- 
ruptly as her father had left her. Carol's preference to be the active leave taker as an identification with the father was acted out in a way that disrupted treatment as her own development had been disrupted. If she returns to treatment she may be able to gain further mastery of her early childhood trauma to lessen the destructive impact on the pattern of her future relationships.

\section{Parental competition/adolescent ambivalence}

Jane, age 16, was a socially active, gregarious adolescent whose father sought help when her grades dropped to a D average in her sophomore year of high school. The youngest of three children with two college age brothers, her parents divorced when she was 9 years old. Until she was 15, her parents continued to live within a block of each other. While she lived at her mother's home, she had ready access to informal visits with her father. Her father remarried when she was 14. Her relationship with her 29-year-old stepmother was amicable but distant. When Jane was 15 , her mother remarried and moved several miles away and out of the school district. The parents reached a decision for Jane to live with her father, assuring continuation in her school system and peer relationships. A more subtle and less explicit reason for the decision was the father and stepmother's belief that while Jane's mother was a friend and confidant to her daughter, her home lacked the structure and discipline that Jane needed to traverse her adolescent years successfully. She was seen as not working up to her potential academically and they wanted to assume the task of enforcing academic expectations. They had identified the locus of the problem in the mother and anticipated that their provision of consistent expectations and discipline would provide the necessary corrective experience for Jane to perform well. Not surprisingly, they were disappointed and angry when after four months it became clear she was not meeting their expectations despite rigorous and enforced four hour daily study times.

Jane presented clinically as a sullen, angry adolescent who resented the pressure she felt under to achieve academically. Almost taken for granted were the obvious impressions of her as an attractive, intelligent, popular adolescent. She perceived her father and stepmother as overachieving, competitive people who were satisfied with nothing less from her than what they had accomplished themselves-graduating from Big Ten universities and obtaining post-graduate degrees. She, however, was content to attend a lesser college which upon questioning was revealed to be her mother's alma mater. She harbored longstanding anger toward and disappointment in her father whom she felt had been emotionally inaccessible to her for years despite close physical proximity. She felt he demanded much and gave little praise or encour- 
REBECCA LOHR

agement in return. Her stepmother was viewed as the rival recipient of father's affection and gifts while she was the castaway Cinderella. Since being with her father, her behavior with adults vacillated from passive submission to quiet opposition, with occasional explosive temper outbursts. She missed daily contact with her mother and correctly perceived her father's wishes to limit their interactions in deference to meeting the requirements of his rigid daily schedule. Masked depression was noted in her frequent somatic complaints and erratic school attendance.

Jane's parents had sustained an adequate co-parenting arrangement since their divorce. The manifest reason for a change in living arrangements seemed realistically based and aimed at serving Jane's educational, emotional and social needs. However, further exploration revealed that the change did not take into account Jane's ongoing dependency needs vis-à-vis her mother and superimposed a rigid structure that fueled and escalated Jane's unresolved anger toward her father since the divorce. Oedipal issues surfaced in Jane's competition with her young stepmother from which she regressed into a passive, oppositional, and defeated position. Father saw in Jane many of the negative characteristics of her mother - undisciplined, unmotivated to excel, and hedonistic. He conveyed conscious and unconscious communications that if Jane did not change her ways she could not receive his love. Jane's adolescent tasks of resolving identity issues and emancipating from her parents were significantly complicated by this emotional scenario. The co-parenting that had successfully continued since the divorce broke down during her adolescence when her father felt compelled to make a concerted effort to wrest Jane away from an identification with her mother.

Short-term work with Jane focused on interpreting her poor academic performance as an expression of long-standing anger toward her father exacerbated by his remarriage and current rigid performance expectations. Her sadness and sullenness lifted somewhat also in response to educative work with her parents aimed at allowing Jane to assume more responsibility for her own schedule and performance, thus attempting to absolve the parent-child struggle and shift the responsibility to Jane to develop more positive autonomous functioning. Jane was resistant to pursuing long-term intervention and assumed a counterdependent stance to ward off intense longings to have someone there for her. She had shifted from looking to adults as sources of support and positive reinforcement to peers with whom she had formed strong attachments. It was decided that it was therapeutically indicated to allow her some control over the length and intensity of treatment. The issue of control versus lack of control over her life was a critical one that colored her adolescent experience. She harbored more than the typical 
amount of adolescent anger and resentment toward parents and other authority figures, and doubted that any adult could give her best interests top priority.

\section{DISCUSSION}

Both Carol and Jane experienced narcissistic assaults when their fathers left their families; Carol at the age of five and Jane at the age of nine. Consistent with literature findings, the loss at five had a more traumatic impact than the loss at nine. During their latency years, peer relationships, relationships with their mothers, and academic achievements appeared in retrospective description to have been age appropriate and successful. It was during early adolescence that Carol's sense of self-esteem and feelings about her femininity emerged as significant issues. For her, to leave her mother and go to her father was to pursue an illusion of good feelings about herself that she had experienced in relation to him during her early childhood. She had maintained an idealized fantasy that included an attitude of forgiveness toward forgotten birthdays and unacknowledged Christmases. These illusions were rapidly shattered when she experienced him as seductive but demeaning, flattering but ungiving. When her father maintained no ongoing contact with her, she experienced a repetition of the early trauma. She was unable to integrate this disillusionment in her father and feelings of failure about herself that resulted until two years after her return to her mother's. Carol's pathology is best described as an identity disorder, or "disorder of the self" that Elson (1986) describes as becoming manifest in adolescence as "low self-esteem, lack of goals, immobilization, or in dangerous acting out behavior, such as substance abuse, delinquency or perversion" (p. 94).

Jane, on the other hand, did not experience a sudden rupture in the relationship with her father when her parents divorced. At the age of nine, she was well-established in latency and her father continued to be a part of her life, albeit not as gratifying an object as she would have wished. He expressed mixed motives in having her live with him and his new wife, on one level wanting to provide Jane with a positive family experience. This change exacerbated Jane's competitive feelings with a new female object in her father's life and evoked sad feelings about the loss of the closeness with her mother. All adolescents have to go through a period of mourning vis-à-vis parental objects. Jane's depressive affects were heightened by the absence of her mother in her daily life and the sharing of father with a woman with whom she felt she could not begin to compete successfully. Blos (1962) concludes that “... the process of detachment is accompanied by a profound sense of loss 
and isolation equivalent to mourning" (p. 125). Her mourning work was intensified by the disruptions in daily contact, however, accessibility to both parents during her adolescence provided support for working through her ambivalence toward them and resolving identity issues.

\section{Father and daughter/shared anxiety about femininity}

Alice was brought to the clinic by her mother when she was 13 years old with the presenting concern of a ten-pound weight loss over a two-month period since returning from her father's for a summer visit. The evaluation revealed that her weight was stabilizing and there was not strong evidence for a diagnosis of anorexia. She was, however, perfectionistic and demanding of herself, a straight $A$ student, and often preoccupied with thoughts about food. She did not like the food prepared by her mother which tended to be high in carbohydrates and fats and she yearned for salads, fresh fruits, and vegetables. She often shopped for her own food, prepared her own meals, and ate alone rather than with her family that included her mother, stepfather, and two-year-old half-sister. She was quite unhappy in this living situation and spoke nostalgically and idealistically of the pleasure she had living with her father until age 12. Her parents divorced when she was two and except for 2-4 week visits with her mother she had lived with her father from the age of 2 until 12. Reasons for her moving to her mother's were vague and unclear to her and also to us initially. What her father communicated to her was that she needed time with her mother during her adolescence to get to know her and have a mother's helping hand during this important phase. As we were later able to piece the story together, her father had ended a six-year relationship with a woman when she became pregnant and he told her he did not want another child to care for, that he had spent 12 years parenting Alice and that he wanted time to invest in his own artistic career. This woman had been a significant maternal figure in Alice's life. The rupture in their relationship, together with Alice's reaching puberty, seemed to precipitate his decision. Alice rationalized his sending her to her mother's, defending him and herself against the rage and feelings of rejection she experienced. Yet, she puzzled over why he sent her to be cared for by a woman who, by his own recounting to her, had experienced psychotic episodes during Alice's first two years of life. Alice had never cathected her mother as a primary object in her life and fought consciously and unconsciously against any identification with her, as to be like her was to be "crazy." Since we had no direct contact with the father, we can only infer from Alice's reconstruction of events what might have compelled her father to make the decision to send her to live with her borderline psychotic mother. Based on evaluation and observation of Alice and her high level of ego 
functioning, it seemed apparent that she had been loved and cared for by her father in a consistent, unambivalent manner until the age of 12 . Alice's internal fantasy about his sending her away was that it had to do with her approaching menarche. Her efforts to forestall menarche by dieting and exercise were with the hope of returning to her father's as an acceptable latency child. She felt the only way to accomplish her goal was to be asexual and ascetic, like a "Catholic nun." Her budding sexuality evoked fear and ambivalence and she established a causal relationship between that developmental event and banishment from her father's home and continuing closeness with him. She felt a profound sense of loss when she left her father and found her mother a less than adequately nourishing object and inadequate feminine identification figure. Alice had to move prematurely into the role of parenting herself. She was unable to communicate her deep sense of unhappiness to her father out of her unconscious fear that she might then be rejected more overtly. He maintained denial and avoidance of her sadness on holiday and summer visits. When Alice attempted to communicate with her mother about feeling insufficiently or ambivalently "cared for," her mother blocked the affective component by responding, "Do you mean maintenance?" Alice's intense rage toward her mother for physically and emotionally abandoning her at the age of two presented itself in disguised dreams of ill befalling her mother. Alice persisted in her hope of returning to her father's for a part of her adolescence to regain her "sanity" before preparing for college, a hope which became realized when she was 15 and her father remarried.

\section{DISCUSSION}

Little has been written about the effects on daughters of having their fathers as the primary parent during their early years. In the case of Alice, she seemed to have received good enough parenting from her father in combination with mother surrogates until the onset of adolescence. Alice's father had to deny and rationalize the basis for the decision to send his daughter to live with a borderline psychotic mother; Alice's adolescent development placed significant stress on his best parental judgment and he used more primitive defenses coupled with society's sanctioning that a girl needs a mother during adolescence. Intervention aimed at dealing with his anxiety and stress might have allowed him to maintain the primary parental role with his daughter. Called in after geographical distance had been set in place, therapy was provided to Alice to help her maintain a positive sense of self and to work on her anxiety and fear about becoming a woman.

Our clinical observations emphasize the critical role fathers play in 
the development and affirmation of femininity in adolescent daughters. The profound negative effect their rejection, ambivalence, seduction, and anxiety have on the development of a positive sense of feminity is strikingly apparent in girls who have experienced parental divorce. Leonard (1966) suggests the need for a girl to "establish a desexualized object relationship to her father" for her to be able later to accept the feminine role without guilt or anxiety and to give love to a young man in her peer group" ( $p$. 332). Without paternal participation the girl may idealize her father and later, as an adolescent, seek a love object similar to the ideal or maintain a preoedipal narcissistic attitude. Such an adolescent is described by Leonard as seeking narcissistic gratification in being loved, but unable to give love.

\section{SUMMARY}

Living arrangements for adolescents whose parents have divorced can, and often do, become a complex arena for playing out parental conflicts as well as phase specific adolescent developmental and divorce related issues. In much of our clinical experience adolescent girls have struggled to make sense of feelings related to parental divorce during their childhood years and to newly experienced traumas during adolescence. The adolescent stage surfaces earlier issues to be reworked as well as introducing new ones to be addressed. Developmental needs of adolescent girls are best met by having access to both male and female parental objects. Fathers play critical roles in aiding the adolescent daughter's individuation from mother and affirming her sense of femininity. In the intact family, girls can relate to each parent and facilitate the adolescent process with much greater ease than if the parents live apart. In divorced families, this may entail physical and geographical moves. Resolution of normative tasks of adolescence is difficult in all families, however, we need to develop awareness of the particular complexities presented in divorced families.

Mental health professionals who work with adolescents and their divorced parents have their own set of tasks:

1. To develop understanding of the resolution of adolescent tasks in family paradigms that differ from the intact natural family, for example adoptive and divorced families.

2. To provide preventive interventions to divorced families at different nodal points. We have discovered that many families and children present for service years beyond the time of the divorce experience, per se. Well-timed interventions at points along the developmental continuum may enhance individual and family func- 
tioning by addressing the specific developmental issues that surface, such as at the time of adolescence.

3. To offer treatment interventions to adolescents and their divorced parents when conflicts emerge that reflect significant internal and/or familial stress. When a change in living arrangements does not bring about the desired and needed internal relief and facilitate developmental progress, therapy can be introduced to explore the conscious and unconscious forces and work toward internal resolutions and living arrangements that best meet the adolescent's developmental needs. Therapy with adolescents has traditionally been deemed challenging and difficult, and adolescents who have experienced parental divorce present unique therapeutic challenges involving problems in forming attachments and trusting relationships, fears of separation and abandonment, and acting out of the defense against the helpless position by aborting treatment or unilateral terminations. Because of the propensity for repetition of early experiences in future relationships, interventions during adolescence before life commitments have been made can reap long-ranging benefits.

\section{REFERENCES}

Anthony, E. J. (1970). The reactions of parents to adolescents and to their behavior. In E. J. Anthony \& T. Benedek (Eds.), Parenthood (pp. 309-324). Boston: Little, Brown $\&$ Co.

Blos, P. (1962). On adolescence. New York: The Free Press.

Chethik, M., Dolin, N., Davies, D., Lohr, R., \& Darrow, S. (1986). Children and divorce: The "negative" identification. Journal of Divorce, 10, 121-138.

Cohen, R. S. \& Balikov, H. (1974). On the impact of adolescence upon parents. In S.C. Feinstein \& P. Giovacchini (Eds.), Adolescent Psychiatry, III (pp..217236S). Chicago: University of Chicago Press.

Derdeyn, A. P. \& Waters D. B. (1977). Parents and adolescents: Empathy and the vicissitudes of development. In S. C. Feinstein \& P. Giovacchini (Eds.), Adolescent Psychiatry, $V$ (pp. 175-185). New York: Jason Aronson.

Elson, M. (1984). Parenthood and the transformation of narcissism in parenthood. In R. Cohen, B. Cohler, \& S. Weissman (Eds.), Parenthood: A Psychodynamic Perspective (pp. 297-314). New York: Guilford Press.

Elson, M. (1986). Self psychology in clinical social work. New York: W. W. Norton \& Co.

Erikson, E. H. (1963). Childhood and society. New York: W. W. Norton.

Freud, A. (1958). Adolescence. Psychoanalytic Study of the Child, 13, 255-278.

Laufer, M. (1977). A view of adolescent pathology. In S. C. Feinstein \& P. Giovacchini (Eds.), Adolescent Psychiatry, V (pp. 243-256). New York: Jason Aronson. Leonard, M. R. (1966). Fathers and daughters. International Journal of Psychoanalysis, 47,
325 -333.

Wallerstein, J. S. (1985), Children of divorce: A preliminary report of a ten year follow-up of older children and adolescents. Journal of the American Academy of Child Psychiatry, 24, 545-553. 
REBECCA LOHR

Wallerstein, J. S. \& Kelly, J. B. (1977). Divorce counseling: A community service for families in the midst of divorce. American Journal of Orthopsychiatry, 47, 4-22.

Department of Psychiatry

University of Michigan Hospital

Ann Arbor, MI 48109 